Fanum

Sociológico
Forum Sociológico

Série II

26 | 2015

Número 26

Caleiras, Jorge (2015), Para lá dos números. As consequências pessoais do desemprego, Coimbra, Almedina

\title{
Carla Valadas
}

\section{CpenEdition}

\section{Journals}

Edição electrónica

URL: https://journals.openedition.org/sociologico/1226

DOI: 10.4000/sociologico.1226

ISSN: 2182-7427

Editora

CICS.NOVA - Centro Interdisciplinar de Ciências Sociais da Universidade Nova de Lisboa

Edição impressa

Data de publição: 12 dezembro 2015

Paginação: $75-78$

ISSN: 0872-8380

Refêrencia eletrónica

Carla Valadas, «Caleiras, Jorge (2015), Para lá dos números. As consequências pessoais do desemprego, Coimbra, Almedina», Forum Sociológico [Online], 26 | 2015, posto online no dia 04 abril 2016, consultado o 31 março 2022. URL: http://journals.openedition.org/sociologico/1226 ; DOI: https://doi.org/10.4000/sociologico.1226 


\title{
Caleiras, Jorge (2015), Para lá dos números. As consequências pessoais do desemprego, Coimbra, Almedina
}

\author{
Carla Valadas* \\ Universidade de Coimbra, Centro de Estudos Sociais (CES-UC)
}

Sociólogo de formação, Jorge Caleiras acumula uma longa experiência profissional nos serviços públicos de segurança social, dedicada entre outras tarefas à implementação de políticas sociais e de emprego. O seu livro Para lá dos números. As consequências pessoais do desemprego resulta da sua tese de doutoramento em Sociologia defendida em 2011 na Universidade de Coimbra. Neste livro o autor propõe-se compreender o lado subjetivo do desemprego. As dimensões de análise privilegiadas incluem o modo como os desempregados vivenciam o desemprego, os significados que atribuem à sua condição, as consequências pessoais por eles sentidas e o tipo de estratégias que desenvolvem para enfrentar a situação em que se encontram ${ }^{1}$.

Nesta obra, Jorge Caleiras aborda dois temas centrais do nosso tempo, o desemprego e a pobreza, mostrando as interligações que podem existir entre ambos e sugerindo a importância de uma análise mais fina das experiências individuais que os dados estatísticos não contam. Sendo o produto final (revisto e sistematizado) de uma investigação de teor eminentemente qualitativo centrada na sociedade portuguesa, faz-nos reconhecer que os diferentes modos como o desemprego é vivido necessitam de ser compreendidos à luz das especificidades do tecido social, económico, político local e também nacional. As dinâmicas específicas de cada espaço estão associadas, entre outros aspetos, às ligações que o Estado, o mercado e a família (ou outros grupos sociais de proximidade) entretecem no apoio e proteção aos desempregados. Num estudo clássico publicado na viragem do milénio sobre os regimes de bem-estar e as experiências de desemprego em oito países europeus (Alemanha, Dinamarca, França, Holanda, Irlanda, Reino Unido, Itália, Suécia) Duncan Gallie e Serge Paugam (2000) exploraram a interligação entre estes elementos assinalando a heterogeneidade das experiências de desemprego. $\mathrm{Na}$ linha entreaberta por estes investigadores, também Jorge Caleiras realça que os efeitos negativos e prolongados de uma situação de desemprego são determinados pelas condições depressivas do mercado de trabalho, pelas características interpessoais dos próprios desempregados e também pelo regime subprotetor de proteção aos desempregados existente num determinado momento histórico (p. 16).

O livro divide-se em três grandes partes, excluindo a introdução e a conclusão. A primeira parte (capítulos I e II) é dedicada a uma contextualização inicial das ideias. Num primeiro momento o autor situa o seu objeto de estudo, relacionando-o com um conjunto de problemáticas e de discussões teóricas atuais. De entre estas sublinho a questão da "indeterminação das fronteiras" que marca a categorização dos indivíduos privados de emprego e aquela que, num contexto de redefinição dos estatutos sociais, se aplica também ao conceito de pobreza e ao de exclusão social, com os quais surge interligado, como demonstram alguns autores (Costa, 1998, 2008; Paugam, 2003). Esta questão associa-se a uma outra discussão em torno da emergência do desemprego como objeto de estudo das ciências sociais e, em particular, da sociologia e também - ainda que o autor o não refira de forma explícita - do papel que o Estado e as políticas públicas desempenham na delimitação das categorias e na determinação da relevância social, económica e política do desemprego.

Num segundo momento, Jorge Caleiras vai ao encontro dos contextos e significados particulares de que o fenómeno do desemprego se reveste em Portugal sublinhando: o seu caráter estrutural; as vulnerabilidades e os dualismos associados ao modelo subprotetor de proteção aos desempregados; os riscos sociais, e não meramente individuais, ligados à desestruturação das relações sociais e ao progressivo afastamento de um certo ideal de cidadania. Partindo da ideia de que "o emprego é um dos principais mecanismos de integração social nas sociedades contemporâneas" (Costa, 1998: 57), o autor reflete sobre a condição dos desempregados, sobre o que significa para muitos perder as relações interpessoais que o emprego proporcionava e, para outros, ver condicionadas as suas perspetivas de construção do futuro (ter um emprego, uma família, etc.). Nestes capítulos iniciais, o autor recorda ainda os mecanismos de amortecimento 
existentes na sociedade portuguesa que permitem aos indivíduos fazer face aos problemas individuais e coletivos provocados pelo desemprego. Perante as vulnerabilidades estruturais e as desigualdades que caracterizam a sociedade portuguesa no domínio da proteção social, o autor realça o papel da família num processo (que se mantém) de partilha de responsabilidades com o Estado; o recurso ao trabalho informal e à agricultura de subsistência como formas de compensar os baixos rendimentos; o crescimento da emigração; a fraqueza e ineficácia das políticas públicas.

Na segunda parte do livro, os capítulos III a VII são dedicados à descrição das experiências biográficas de um conjunto circunscrito, ainda que internamente distinto, de indivíduos desempregados na zona centro de Portugal. Nos capítulos III e IV o autor retrata as trajetórias de vida dos 36 indivíduos (homens e mulheres) entrevistados no que diz respeito aos seus percursos escolar e profissional. Os testemunhos pessoais dão conta dos significados subjetivos e da perceção que estes desempregados reproduzem a respeito da sua condição social e dos efeitos que decorrem da situação de desemprego em que se encontram.

Para além de aspetos comuns que todos partilham, o autor mostra (capítulos V, VI e VII) como as consequências pessoais do desemprego podem assumir contornos diferentes em função, nomeadamente: do território de pertença; de um conjunto de características interpessoais e profissionais; do tempo de duração do desemprego; e, finalmente, dos mecanismos de apoio institucionais e financeiros a que se tem acesso. Estas diferenças e os inter-relacionamentos que elas suscitam poderiam levar à identificação de diferentes grupos ou "tipos" de desempregados cujas circunstâncias (pessoais, institucionais) específicas deveriam ser acauteladas na forma como as políticas públicas e/ou outro tipo de respostas sociais, empresariais são concebidas e implementadas. A construção de tipos-ideais revela-se um instrumento útil de observação e eventual reclassificação da sociedade desenvolvido há mais de um século por um dos autores clássicos da Sociologia, Max Weber. Ainda que este não tenha sido um exercício tentado pelo autor neste livro, em meu entender a construção de tipos-ideais constitui um instrumento pertinente de interpretação do problema do desemprego e das suas consequências no tempo atual, que carece de ser testado em estudos de maior amplitude sobre o desemprego na sociedade portuguesa ${ }^{2}$.

Na transição para a parte final do livro, Jorge Caleiras sistematiza e compila algumas das ideias da pesquisa empírica que realizou distinguindo aquilo a que chama "estratégias ativas" de resposta ao desemprego de "estratégias-limite perspetivadas" (p. 109). O acionamento destas estratégias e/ou "mediadores de compensação", como Ihes chamaram Gallie e Paugam (2000), depende de fatores internos e externos aos indivíduos que o autor descreve, mais em detalhe, no capítulo IX.

A última parte do livro inclui os dois capítulos (capítulos X e XI) que precedem a conclusão. Nestes o autor apresenta-nos uma visão acerca do modo como alguns dos atores centrais na implementação das políticas públicas percecionam as interligações entre desemprego e pobreza. Esta parte do trabalho é construída a partir de dados empíricos resultantes de entrevistas semidiretivas a dirigentes de Núcleos Executivos do Programa Rede Social, de Presidentes de Câmaras Municipais e de dirigentes sindicais e patronais (capítulo $X$ ). No capítulo subsequente, estes vários olhares são complementados pelos dos representantes de instituições públicas de emprego e segurança social entrevistados. A análise do modo como estes atores intervêm junto dos desempregados e concebem o seu próprio papel transporta consigo algumas ideias que importa sublinhar: 1) as instituições intervêm de forma fragmentada; 2) o processo de estigmatização que alia a situação/condição vulnerável de muitos desempregados a uma fraca (e persistente) motivação para o trabalho é reforçado pelos técnicos e representantes das instituições e é, em certa medida, usado como autojustificação dos limites de ação dos serviços; 3) existem mecanismos de diferenciação interna (desempregados ativos/empreendedores-desempregados inativos/ /desesperançados/pouco motivados; desempregados-empregados à procura de um novo emprego) que levam os técnicos de emprego a aplicar estratégias diferentes e a estabelecer prioridades distintas; 4) o peso do trabalho burocrático e as exigências técnicas que uma abordagem individualizada, (idealmente) eficaz e alargada a um número crescente de indivíduos representa para os próprios técnicos são hoje muito relevantes.

Esta parte do livro apresenta-nos uma imagem acerca das mudanças que têm ocorrido não apenas no que diz respeito ao papel (esperado versus efetivamente realizado) de atores centrais que intervêm na implementação das políticas de emprego, mas também do modo como o mercado de trabalho funciona e se (re)organiza. Problemas sociais complexos como são o desemprego e a pobreza carecem de uma intervenção integrada, capaz de incorporar e aproveitar os recursos humanos, físicos, materiais, disponíveis e específicos de um determinado contexto temporal e espacial. Esta é, na minha perspetiva, uma das reflexões que devemos retirar da análise que, neste momento quase final do texto, o autor nos apresenta.

O último capítulo é dedicado às conclusões do trabalho. Estas estão organizadas em torno de alguns tópicos, de entre os quais destaco: efeitos individuais e sociais do desemprego; estratégias 
usadas para lidar com o problema; fatores intrínsecos e extrínsecos que determinam diferentes níveis de vulnerabilidade; a autoconstrução de uma imagem (do "desempregado remediado"?).

Indo mais além de uma mera descrição das ideias, penso que esta parte do texto se predispõe à reconstrução de algumas pontes com estudos pioneiros sobre a sociedade portuguesa. De entre estes destacaria a imagem de uma sociedade estruturalmente dual desenvolvida por Adérito Sedas Nunes nos anos 60 do século passado (Nunes, 1964) e, já mais próximos no tempo, o retrato e as especificidades de uma sociedade semiperiférica desenvolvidos por investigadores do Centro de Estudos Sociais da Universidade de Coimbra (Santos, 1993, 2001).

Para além das mudanças que ocorreram desde essa altura e que resultam da conjugação entre processos externos, transnacionais e outros de ordem interna, alguns dos traços de uma sociedade moderna ou mesmo pós-moderna e, simultaneamente, pré-moderna mantêm-se. Por exemplo, como forma de colmatar, em parte, as fraquezas da intervenção do Estado e das suas políticas, a chamada "sociedade-providência" (agora eventualmente reconvertida em "família-providência") continua a desempenhar um papel muito ativo. Hoje, tal como no passado, continuam também a ser (re)ativadas estratégias tradicionais que incluem desde o recurso à economia informal ou à agricultura de subsistência (embora numa escala mais reduzida), à emigração ou às ajudas financeiras e emocionais providas pela família e/ou por redes informais de proximidade.

No livro sugere-se também a separação, hoje em dia menos explorada na pesquisa em sociologia, entre o mundo rural e o mundo urbano que, aqui e ali, o autor usa para explicar que os efeitos do desemprego são, em certa medida, atenuados e as situações de rutura social e económica mais graves proteladas no tempo ou mesmo contidas graças a mecanismos de entreajuda, formas de compensação alternativas e por meio de processos de relativização da própria situação de privação material (sinal de uma sociedade onde a pobreza massiva é ainda dominante) típicos do espaço rural.

Outro dos temas relevantes que podemos fazer (re)emergir tem que ver com o modo como se estruturam as relações entre homens e mulheres. Sobretudo entre os desempregados mais velhos, a aparentemente velha distinção entre o espaço da casa e o espaço do trabalho parece estar de regresso, implicando, para algumas mulheres, um retrocesso em termos do estatuto social alcançado por via do emprego (anterior). Por outro lado, no entrecruzamento entre as variáveis idades e níveis de qualificação, por exemplo, surgem novas formas de desigualdade refletidas em diferentes formas e oportunidades de participação no mercado de trabalho. Os mais jovens, apesar de, em alguns casos, apresentarem níveis de qualificação mais altos, encaram com muitas limitações as possibilidades e condições de inserção no mercado de trabalho.

Há ainda outro traço distintivo que podemos desvendar na imagem de "círculo vicioso" que subjaz a muitos dos percursos biográficos descritos por Jorge Caleiras. Neles podemos reencontrar as marcas da "cultura da pobreza" imortalizada (não sem contestação) por Oscar Lewis (Lewis, 1966). Trajetórias de empregos precários, intercaladas por momentos prolongados de desemprego, pequenos biscates, etc., perpetuam-se ao longo de um tempo relativamente longo que marca a vida familiar e condiciona as oportunidades de ingresso/regresso ao mercado de trabalho de muitos indivíduos.

Em linha com outros estudos sociológicos que se debruçam sobre o caráter subjetivo do desemprego (Demazière, 1995; Paugam, 2003), Jorge Caleiras reflete sobre as consequências pessoais do desemprego e a sua relação com a pobreza e, acrescentaria, a exclusão social. Uma das ideias finais do autor é a de que "a esmagadora maioria das situações são consideradas como más ou razoáveis, mesmo que de um ponto de vista objetivo sejam más ou mesmo muito más" (p. 205). No fundo, diz-nos Jorge Caleiras que nem sempre e nem todos os desempregados reconhecem pertencer à categoria de "pobres" e que a deterioração da condição económica de muitos dos seus entrevistados não está necessariamente associada ao isolamento social e à rutura dos laços sociais tal como poderíamos esperar. Em meu entender, esta conclusão deve ser lida com cautela, tendo em conta os limites metodológicos do próprio estudo (a impossibilidade de generalização à sociedade portuguesa no seu todo e a ausência de um estudo de tipo longitudinal). Se reconhecermos que o estigma social, a par da degradação da situação material e da própria condição mental, atravessa muitas das experiências vividas do desemprego retratadas no livro, podemos antes pressupor que estamos perante um processo de marginalização contínuo em que se vão verificando várias ruturas. Nesta mesma linha, o lado invisível de uma "pobreza envergonhada" que continua bem presente na nossa sociedade deve levar-nos a questionar os nossos instrumentos de análise e a recolocar no centro da análise sociológica a relação entre (nova) pobreza - exclusão social - desemprego emprego precário.

Em ligação com estas ideias há ainda outro tema, hoje amplamente discutido embora nem sempre a partir do olhar da sociologia, ligado ao papel e à (in)eficácia das políticas públicas e às alterações nos modelos de estado-providência. Sobre esta problemática Jorge Caleiras deixa-nos algumas pistas metodológicas a explorar sobre o papel dos serviços, os novos princípios orientadores das medidas, o 
afastamento entre a conceção e implementação das políticas, a ausência continuada de uma intervenção integrada por parte das instituições.

Ainda que o livro não tenha a pretensão (e o autor, de certo modo, assume-o) de contribuir para o desenvolvimento de grandes teorias e/ou pistas que possam não só informar como também influenciar as escolhas humanas e os comportamentos sociais ${ }^{3}$, tem sem dúvida o mérito de nos fazer recordar como é importante nas nossas investigações darmos voz aos atores, situarmo-nos (também) numa escala micro - aquela em que precisamente as políticas (públicas) se traduzem em ações concretas e que envolve atores sociais concretos.

Por tudo isto considero que esta é uma obra que os estudantes de sociologia, política social, economia devem ler como forma de desenvolverem um pensamento crítico que lhes permita ir além das estatísticas.

\section{Notas}

1 Sobre este tipo de análise os trabalhos de Didier Demazière $(1995,2006)$ constituem referências importantes.

2 Os autores de um estudo recente (Valadas et al., 2014) procuraram fazê-lo, numa investigação de teor exploratório, a propósito das diferentes estratégias e formas de lidar com o desemprego por parte da população estrangeira presente no território português.

3 Para alguns autores este deve ser o intuito primordial e de certa forma distintivo da Sociologia (Watson, 2008).

\section{Referências bibliográficas}

COSTA, A. B. (1998), Exclusões Sociais, Lisboa, Gradiva.

COSTA, A. B. (ed.) (2008), Um olhar sobre a Pobreza. Vulnerabilidade e Exclusão Social no Portugal Contemporâneo, Lisboa, Gradiva.

DEMAZIÈRE, D. (1995), La Sociologie du Chômage, Paris, La Découverte.

DEMAZIÈRE, D. (2006), Sociologie des chômeurs, Paris, La Découverte.

GALLIE, D. e S. Paugam (2000), Welfare Regimes and the Experience of Unemployment in Europe, Oxford, Oxford University Press.

LEWIS, O. (1966), The Children of Sánchez, Autobiography of a Mexican Family, Nova Iorque, Random House.

NUNES, A. S. (1964), "Portugal, sociedade dualista em evolução", Análise Social, 2 (7-8), pp. 407-462.

PAUGAM, S. (2003), A desqualificação social: ensaio sobre a nova pobreza, Porto, Porto Editora.

SANTOS, B. de S. (ed.) (1993), Portugal: um retrato singular, Porto, Afrontamento.

SANTOS, B. de S. (org.) (2001), Globalização: Fatalidade ou Utopia? (Vol. 1, A Sociedade Portuguesa Perante os Desafios da Globalização), Porto, Edições Afrontamento.

VALADAS, C. et al. (2014), Quando o trabalho desaparece: imigrantes em situação de desemprego em Portugal (Vol. 55), Lisboa, Alto Comissariado para as Migrações, I. P. (ACM, I. P.).

WATSON, T. (2008), Sociology, Work and Industry (5. a ed.), Londres e Nova Iorque, Rutledge.

* Bolseira de pós-doutoramento da Fundação para a Ciência e a Tecnologia - SFRH/BDP/85967/2012.

Carla Valadas (csvaladas@gmail.com). Universidade de Coimbra, Centro de Estudos Sociais (CES-UC). Colégio de S. Jerónimo, Largo D. Dinis, Apartado 3087, Gabinete 22, 3000-995 Coimbra, Portugal. 